\title{
O imaginário do sangue e de sua pureza na antiga França ${ }^{12}$
}

\author{
Arlette Jouanna ${ }^{3}$
}

A palavra sangue, na França dos primeiros tempos modernos, por um lado designava o líquido vital que corria nas veias, e por outro a linhagem, a "raça". O sangue era com efeito considerado o veículo das qualidades físicas e morais hereditárias que caracterizavam a personalidade de uma linhagem. Sua pureza devia facilitar o exercício das virtudes. Essa crença permitia explicar a superioridade da nobreza e afirmar que a hierarquia social era justa, já que natural; era igualmente ela que legitimava o poder dos reis, caracterizados pela excelência de seu sangue.

Palavras-chave: Limpeza de sangue - raça - hierarquias sociais.

\section{The imaginary of blood and its purity in old France}

The term blood in France during the early modern times designated, on one side, the vital fluid that ran in our veins, and on the other lineage, "race". Blood was in fact seen as the vehicle of hereditary physical and moral qualities that marked a lineage's character. Its purity should encourage the practice of virtues. This idea helped explain the superiority of nobility and backed the statement that social hierarchy was a fair notion, for being natural; it legitimized the power of kings as well, who were characterized by the excellence of their blood.

Keywords: Blood purity - race - social hierarchies.

\footnotetext{
${ }^{1}$ Artigo recebido e aprovado para publicação em julho de 2010.

${ }^{2} \mathrm{O}$ presente texto foi objeto de uma apresentação durante o colóquio organizado de 14 a 16 de janeiro de 2010 na Universidade de Paris IV pelos professores Annie Molinié e Raphaël Carrasco intitulado "La pureté de sang" en Espagne. Du lignage à la "race" a ser publicado na coleção Ibérica, das Presses Universitaires da Sorbonne.

${ }^{3}$ Professora da Université Montpellier III - e-mail : arlette.jouanna@wanadoo.fr
} 


\section{L'imaginaire du sang}

Le mot sang, dans la France des premiers temps modernes, signifiait d'une part le liquide vital qui coulait dans les veines et d'autre part le lignage, la "race". Le sang était en effet considéré comme le véhicule des qualités physiques et morales héréditaires qui faisaient la personnalité d'une lignée. Sa pureté était censée faciliter l'exercice des vertus. Cette croyance permettait d'expliquer la supériorité de la noblesse et d'affirmer que la hiérarchie sociale était juste puisque qu'elle était naturelle; elle légitimait également le pouvoir des rois, caractérisés par l'excellence de leur sang.

Mots-clé: Pureté de sang - race - hiérarchies sociales.

O vocábulo sangue, na França dos primeiros tempos modernos, tinha duas acepções complementares. O dicionário de Furetière, publicado no final do século XVII, as distinguia de forma precisa. Por um lado, esse vocábulo designava "o mais nobre dos quatro humores que existem no corpo dos animais". A segunda acepção era assim definida: "diz-se também do parentesco, da raça e da comunicação estabelecida pelo sangue através das gerações".

Essa polissemia é reveladora: ela sugere que o sangue constitui a própria essência de uma linhagem, sua personalidade transmitida pela herança. $\mathrm{O}$ termo raça mencionado por Furetière traduz muito bem tal aspecto; esse vocábulo, que surgiu no século XV por influência da palavra italiana razza, origina-se provavelmente do latim ratio no seu sentido de "categoria", espécie, e no sentido de "descendência do" latim médio. Ele expressa assim perfeitamente a crença na especificidade das linhagens humanas: homens caracterizados por suas qualidades físicas e morais hereditárias. Essa convicção permitia decifrar o sentido que se procurava perceber na sociedade. Na qualidade de crença, ela se baseava mais na interpretação de um sistema de sinais ${ }^{4}$ do que em provas racionalmente argumentadas. Além disso, as próprias teorias médicas sobre a realidade biológica do sangue contribuíam para alimentar essa visão do mundo. Convém, portanto, começar pela exposição dessas teorias. Sendo assim, evocaremos o imaginário que se prendia a elas. Procuraremos inicialmente examinar a forma pela qual esse imaginário legitimava a ordem social e, em seguida, examinar em que medida ele aportava argumentos ideológicos de luta pelo poder.

\footnotetext{
${ }^{4}$ Permito-me fazer referência à minha tese, L'idée de race en France au XVI siècle et au début du XVII ${ }^{\mathrm{e}}$ publicada em 1976 pelo Departamento de Publicações da Universidade de Lille III, reeditada em 1981 pela Presses de l'Université de Montpellier III (2 volumes), e publicada parcialmente sob o título Ordre social. Mythes et hiérarchies dans la France du XVI siècle. Paris: Hachette, 1977.
} 


\section{O sangue, um humor purificado}

O sangue, como lembrava Furetière, era considerado um dos quatro humores que constituía o corpo, sendo os outros a fleuma ou pituíta, a bile amarela ou cólera e a bile negra ou melancolia. Esses humores, de acordo com a medicina hipocrática-galênica, estavam associados a qualidades (calor, frio, secura e umidade) e a elementos (ar, água, fogo e terra). Uma figura inserida por Ambroise Paré, na sua Introduction ou entrée à la vraye cognoissance de la chirurgie, estabelecia uma correspondência entre o sangue e o ar quente e úmido; a fleuma e a água fria e úmida; a cholera e o fogo quente e seco; e finalmente entre o humor melancólico e a terra fria e seca. ${ }^{5}$

Desses quatro humores, o sangue era o mais perfeito. Antes da descoberta de sua circulação no corpo, acreditava-se que ele se esgotava após atingir todos os membros. Era, pois, necessário regenerá-lo permanentemente mediante a ingestão de alimentos. O sangue era gerado ao final de um processo de refinamento. Uma primeira etapa resultava na produção daquilo que era chamado de "massa sanguinária" designada também sob o nome de chyle, substância esbranquiçada "semelhante ao leite de amêndoas", dizia Paré, e na composição da qual entravam os quatro humores. Em uma segunda etapa, essa massa era purificada e purgada das duas biles e da fleuma. Restava então uma "substância vermelha semelhante ao vinho", que era o sangue propriamente dito. Essas duas operações se processavam no fígado e no coração. Os autores, entretanto, dividiam-se quanto à ordem desse processamento. Ambroise Paré, seguindo Galeno, situava a primeira no corpo e a segunda no fígado. Por sua vez, Rabelais, cujo Terceiro Livro evoca de maneira bem humorada a gênese do sangue, sustentava, como Aristóteles e Hipócrates, a primazia do coração. ${ }^{6}$ Em seu dicionário, Frutière registrava: "Não se decidiu ainda, em anatomia, se é o coração ou o fígado que produz o sangue."

O importante é que, de acordo com essa concepção, o sangue era o humor mais refinado. Ele se encontrava, portanto, na fronteira do corporal com o espiritual. Sua natureza sutil o tornava próprio a veicular as substâncias aéreas cha-

\footnotetext{
${ }^{5}$ Ambroise Paré, Introduction ou entrée à la vraye cognoissance de la chirurgie, prefácio da edição das Euvres de 1575 (Paris, Gabriel Buon), em Euvres complètes, ed. Jean-François Malgaigne. Paris, J.-B. Baillère, t. I, p. 32 et seguintes.

${ }^{6}$ Rabelais, "Le Tiers Livre”, capítulo IV, CEuvres Completes, ed. Jacques Boulenger, Paris, Gallimard (Bibliothèque de la Pléiade), 1955, pp. 345-46 (ed. brasileira: Ateliê Editorial, 2006).
} 
madas de "espíritos" (os pneumas da tradição galênica): o espírito natural era produzido pelo fígado, o espírito vital provinha do coração e o espírito animal emanava do cérebro. ${ }^{7}$ A descrição desses espíritos por Ambroise Paré dá perfeitamente conta de sua essência semimaterial e semi-imaterial: "O espírito é uma substância sutil, aérea, transparente e luzidia, feita da parte mais leve e tênue do sangue, para que através desta, a virtude das faculdades principais que governam nosso corpo seja conduzida e levada às outras partes do mesmo a fim de que ali possam dar início à sua própria ação". ${ }^{8}$

Os espíritos serviam de intermediários entre o corpo e a alma. O neoplatonismo e sua mística da unidade auxiliavam os humanistas a pensarem na sua junção. Marsílio Ficino, que tinha sido médico, descrevia a alma em termos poéticos:

A alma, sendo ela própria puríssima, como o ensina a verdadeira filosofia, está unida a esse corpo grosseiro e terroso, tão diferente dela, tão somente por uma espécie de corpúsculo etéreo e diáfano que chamamos de "espírito", nascido sob a influência do calor do coração, da parte mais límpida do sangue e distribuído em seguida pelo conjunto do corpo. A alma, insinuando-se facilmente nesse "espírito", que possui muitas afinidades com ela, espalha-se inicialmente e por inteiro nele, passando em seguida, por seu intermédio, ao conjunto do corpo ao qual dá antes de mais nada a vida e o movimento, tornando-o vital. E é através dele que ela governa e movimenta o corpo. E tudo que passa do corpo para esse "espírito", a alma, estando presente, o percebe imediatamente."

O sangue era, portanto, o resultado de uma filtragem das impurezas corporais e, como dizia Rabelais, a "sede da alma". ${ }^{10}$ Ele concentrava em si mesmo toda a essência de uma pessoa. E a teologia cristã do sangue do Cristo consolidava ainda mais essa valorização do sangue humano.

A qualidade dos alimentos ingeridos tinha muita importância, já que eram eles que forneciam a matéria-prima do sangue. Quanto mais delicada a alimentação, mais a depuração tinha chances de ser eficaz. Essa exigência favorecia evidentemente as elites, aquelas que podiam usufruir de alimentos mais refinados. O filósofo e médico Symphorien Champier (1471-1538) recomendava que

\footnotetext{
${ }^{7}$ Ver a excelente síntese sobre as teorias médicas do sangue por Pierre Camel, Le Sang embaumé des roses. Sang et passion dans la poésie amoureuse de Pierre de Ronsard, Genève, Droz, 2004, pp. 26-68.

${ }^{8}$ A. Paré, "Introduction ou entrée à la vraye cognoissance de la chirurgie", op. cit., p. 39.

${ }^{9}$ Marsílio Ficino, Théologie platonicienne de l'immortalité de l'âme, ed. Raymond Marcel, Paris, les Belles Lettres, 1964-1970, VII, chap. VI, p. 274, citado por M. Carnel, Le Sang embaumé des roses, op. cit., p. 88.

${ }^{10}$ Rabelais, Le Tiers Livre, ed. citada, pp. 344-5.
} 
o príncipe não fosse alimentado "grosseiramente, como o popular". ${ }^{11}$ Giovanni Battista Possevino, o autor do influente Dialogo dell'honore publicado em Veneza, em 1553 e traduzido para o francês em 1557 por Claude Gruget, constatava que a nobreza tinha a possibilidade de "usufruir boas carnes, as quais acabam posteriormente tornando os espíritos mais sutis e aptos a adquirir as virtudes". ${ }^{12} \mathrm{O}$ jurista Florentin Thierriat, que se considerava nobre, afirmava em 1606: "A caça nos sendo permitida, comemos mais perdizes e outras carnes delicadas do que eles [os plebeus], o que nos proporciona sentidos e inteligência mais sutis do que naqueles que se nutrem de carne de boi ou de porco." ${ }^{13}$ Um médico espanhol, por sua vez, cuja obra foi traduzida duas vezes em francês, Juan Huarte, insistia na influência da alimentação não apenas sobre o sangue, mas também sobre o sêmen: era necessário, segundo ele, "fazer uso de carnes delicadas, e na temperatura exigida pelo espírito, porque é dessas carnes que o sangue é gerado, dele que provém o sêmen, e deste último a criatura: e se os alimentos forem delicados e de bom temperamento, assim também será o sangue, e desse sangue o sêmen, e de tal sêmen tal cérebro." ${ }^{14}$

A exigência de uma boa alimentação se revestia de um aspecto particular no caso dos lactentes. O leite era, com efeito, considerado um sangue menstrual refinado: sua pureza influía na qualidade do sangue da criança. Eis como Jacques Guillemeau, médico discípulo de Ambroise Paré, aconselhava as mães a aleitar os filhos: "A melhor solução seria que a criança fosse alimentada por sua própria mãe, ao invés de sê-lo por uma outra mulher, porque seu leite que é apenas sangue branqueado (do qual essa criança foi feita e alimentada por nove meses no ventre de sua mãe) lhe é mais familiar e natural do que o de uma outra mulher." Se a mãe não podia amamentar, era preciso bem escolher a ama-de-leite. Ainda segundo Guillemeau era necessário, nessa escolha, "levar em consideração seis

\footnotetext{
${ }^{11}$ Symphorien Champier, Le gouvernement et régime d'un jeune prince, $1502, \mathrm{f}^{\circ} \mathrm{XX} \mathrm{r}^{\circ}$.

${ }^{12}$ Les Dialogues d'Honneur de Jan Baptiste Possevin [...] mis en françois par Claude Gruget. Paris, J. Longis, 1557, fol. 153v. O livro foi publicado em Veneza sob o nome de Giambattista Possevino, mas foi redigido principalmente por seu irmão, o jesuíta Antonio.

${ }^{13}$ Florentin Thierriat, Trois Traictez, sçavoir: 1. De la noblesse de race. 2. De la noblesse civille. 3. Des immunitez des ignobles. Paris: L. Bruneau, 1606, p. 47-8.

${ }^{14}$ Juan Huarte, L'Examen des esprits pour les sciences [...] nouvellement traduit (por Vion d'Albray). Paris: J. Guignard, 1665, p. 687. A obra de Huarte foi inicialmente traduzida por Gabriel Chappuys, sob o título Anacrise ou parfait jugement et examen des esprits propres et naiz aux sciences, Lyon, F. Didier, 1580.
} 
fatores: a linha de parentesco da ama-de-leite, sua pessoa, seus costumes, seu espírito, seu leite e seu filho". A "linhagem e o parentesco" vinham em primeiro lugar: a ama-de-leite devia "ter sido gerada por uma raça bem sadia". ${ }^{15}$ Essa opinião era bastante propalada. Com efeito, Michel de l'Hospital, em uma Epístola redigida em verso e enviada ao seu amigo Jean Morel, afirmava que os defeitos que aparecem numa criança de "boa casa" provinham em parte do hábito de aleitá-los com uma ama-de-leite de "vil condição". ${ }^{16}$

A associação dos humores, das qualidades e dos elementos constituía a compleição ou o temperamento. A compleição, segundo se acreditava, influenciava as funções intelectuais e psíquicas como o ensinara Galeno no tratado intitulado Que les meurs de l'âme suyvent la temperature du corps, traduzido por Jean Le Bon, em 1557. Esta era também a opinião de Ambroise Paré. Pierre de Lostal, um discípulo de Gerolamo Cardano, utilizava, para facilitar a compreensão desse fenômeno, a imagem de uma vela que brilhava mais ou menos conforme estivesse queimando dentro de um vaso transparente ou de um vaso opaco. ${ }^{17}$ David Rivault de Fleurance, que foi preceptor de Luís XIII, salientava a importância de possuir um corpo bem disposto:

Enquanto o animal imortal (como o chama Platão) estiver encerrado nessa prisão mortal, ele precisará necessariamente tirar do corpo a elegância ou a feiúra de suas ações, e só poderá entrar na alma através da espessura daquele que lhe serve de órgão para suas operações, e de tal forma que ela [alma] exercerá essas ações de modo melhor ou pior dependendo da boa ou má disposição [do corpo]. Um corpo lento, pesado, grosseiro ou mal proporcionado dificulta em muito a sutileza do espírito, e constitui um obstáculo a várias virtudes. ${ }^{18}$

Existiam, portanto, compleições favoráveis ao exercício das qualidades intelectuais e morais, e outras que constituíam um obstáculo a esse exercício. Os “bem

15 "Les Euvres de chirurgie de Jacques Guillemeau, chirurgien ordinaire du roy", In: Le Gouvernement de la femme enceinte durant les neuf mois de sa grossesse. Et le moyen de la secourir és maladies qui luy peuvent survenir durant le temps d'icelle Rouen, chez Jean Viret, 1649, cap. I, p. 391.

${ }^{16}$ Michel de L'Hospital, Poésies complètes, trad. e ed. por Louis Bandry de Nalèche, Paris, Hachette, 1857, livro III, obra poética II, p. 163. A mesma opinião é formulada por Jean de Saulx-Tavannes (Mémoires de Gaspard de Saulx, Paris, Michaud et Poujoulat, 1838, p. 52, col. 1).

${ }^{17}$ Les Discours philosophiques de Pierre de Lostal, sieur d'Estrem, Paris, 1579, p. 39, citado por Henri Busson, Le Rationalisme dans la littérature française de la Renaissance, Paris, Vrin, 1957, p. 394.

${ }^{18}$ David Rivault de Fleurance, Les Estats, esquels il est discouru du prince, du noble et du tiers estat conformement a nostre temps. Lyon, B. Rigaud, 1596, p. 272. 
nascidos" beneficiavam-se desde o nascimento de uma feliz compleição, como dizia o poeta e filósofo francês Etienne de La Boétie: "Não se pode negar", escrevia ele no Discurso sobre a servidão voluntária, "que a natureza nos domina em grande parte, bem ou mal nascidos, para nos levar onde ela quer e nos fazer dizer o que quer." ${ }^{19}$ Da mesma forma, para o jurista Louis le Roy, tradutor e comentador da Política, de Aristóteles, os "bem nascidos e bem condicionados" eram superiores àqueles "cujas afeições são servis e rebeldes à razão". ${ }^{20} \mathrm{O}$ historiador La Popelinière, que se dizia fidalgo, chegava a afirmar que os nobres tinham particular predisposição, em razão de sua compleição, a escrever a história, pois sendo "da melhor massa, naturalmente bem constituídos e possuindo espírito mais ágil e não tanto apegado às coisas grosseiras e terrestres, [eles] elevam-se à consideração do que é mais bonito e mais elogiável". Em suma, eles são "mais espirituais e suficientes".

A influência dos dons naturais levantava a questão do determinismo do nascimento. Aqueles que tomavam posição, no antigo debate sobre o papel respectivo do inato e do adquirido, acompanhavam geralmente a opinião expressa por Plutarco, nas suas Obras Morais, segundo a qual três elementos entravam em partes iguais na gênese do homem digno desse nome: a natureza, a educação e a prática regular da virtude. ${ }^{22}$ Com exceção de um pequeno número de autores, como o jurista e escritor bretão Noël du Fail (1520-1591) ou o historiador borgonhês Pierre de Saint-Julien de Balleure (1519-1593), que acreditavam que a virtude acompanhava inelutavelmente um nascimento aristocrático, a maioria estimava que uma boa natureza nada mais é do que uma aptidão inata à virtude, que uma má educação poderia abortar. ${ }^{23}$

Sem entrar no mérito desse debate, vale a pena observar aqui a recorrência, nos juízos sobre a importância das disposições corporais, das noções de apuramento, de leveza, de espiritualização, em oposição aos juízos sobre a grosseria, o peso e a materialidade. Essa importância corresponde àquela do processo de purificação

${ }^{19}$ Étienne de La Boétie, Discours de la servitude volontaire, ed. André et Luc Tournon, Paris, Vrin, 2002, p. 35.

${ }^{20}$ Louis Le Roy, Les Politiques d'Aristote, Paris, M. Vascosan, 1568, p. 47.

${ }^{21}$ Henri Lancelot Voisin, senhor de La Popelinière, L'Idée de l'Histoire accomplie (1599), Paris, Fayard, 1989, p. 231 et 194-196.

${ }^{22}$ Plutarco, Les CEuvres morales et Meslées, trad. por Jacques Amyot, Paris, M. de Vascosan, 1575, fol. $1 \mathrm{v}^{\circ}$.

${ }^{23}$ A. Jouanna, L'idée de race, op. cit., $1^{\text {a }}$ parte, Cap. 2. 
que era considerado a origem da produção do sangue. A expressão "pureza do sangue" traduzia essa valorização. O jurista Le Caron fala, portanto, da "pureza de um sangue nobre e ilustre”. Para o magistrado e poeta Claude Expilly, a nobreza é "o sangue mais puro do Estado". Um outro advogado, Louis Dorleans, evoca, com relação aos fidalgos, "esse sangue mesclado de flor-de-liz, o sangue mais generoso e valoroso que jamais existiu, e o sangue mais puro e mais inflamado que já habitou um corpo de nosso Reino". ${ }^{24}$ Inversamente, o sangue dos plebeus era por vezes descrito como "ruim e infecto"(de malo et infecto sanguine) ou então vil. ${ }^{25}$

Entretanto, na França, a noção de pureza do sangue não recebeu um conteúdo religioso, como no sistema das castas hindus, nem era tampouco afetada pelas clivagens entre o sangue judeu, mouro e o sangue cristão-velho como na Espanha. Ela tinha um sentido essencialmente moral e social e era referida a uma escala de qualidades humanas na qual os nobres ocupavam uma posição superior. Ela assegurava, conforme acreditavam, a coincidência entre a hierarquia social e a hierarquia das virtudes: assim, a ordem da sociedade aparecia como fundamentalmente justa, já que a natureza (e por detrás dela Deus, criador do universo) perpetuava nas posições mais elevadas as famílias dotadas das melhores qualidades. A superioridade social não repousava na força, mas sim na preeminência da virtude; ela tinha, portanto, um caráter edificante, susceptível de uma leitura ética.

Essa ideologia da pureza aplicada ao corpo do fidalgo não deixa de ter seus paradoxos. Ela contrasta com a imagem guerreira que se fazia desse corpo na Idade Média e na Renascença. Como bem lembrou o pesquisador Georges Vigarello, na História do Corpo, que ele codirigiu: "No alvorecer da França moderna, o vigor corporal e suas manifestações continuam a ser um sinal de poder. É impossível descrever um grande personagem, sem que sejam evocadas sua força física, sua resistência ao cansaço e suas proezas. Ele precisa provar sua solidez, sua força. Ele deve exibir valentia [...]: deve ser bem feito de corpo ou de membros. Trata-se

${ }^{24}$ Louis Le Caron, Pandectes ou Digestes du droict françois, Paris, P. L'Huillier, 1607, p. 421; Claude Expilly, $31^{\circ}$ arrazoado (julho de 1601), In: Plaidoyez, $2^{\mathrm{a}}$ edição, Paris, Vve A. L'Angelier, 1612, p. 363; Louis Dorléans, Plaidoyé des gens du roy faict en Parlement en plaine audience, toutes les chambres assemblées le 22. jour de decembre mil VC quatre vingt douze, Paris, Jehan Musar, 1593, p. 120.

${ }^{25}$ Barthélemy de Chasseneux, Catalogus gloriae mundi, Lyon, 1529, t. II, fol. $12 \mathrm{v}^{\circ}$ na edição de 1506, Frankfurt, S. Feyerabendius (pelo sangue "ruim e infecto" dos inferiores); François de Belleforest, L'Histoire des neuf Roys Charles de France, Paris, P. L’Huillier, 1569, p. 356: “Os pequenos são fáceis de dobrar, tanto pela pouca experiência, quanto por sentir não se sabe que vileza do sangue que os leva para coisas semelhantes e iguais ao lugar de onde eles saem". 
de ser 'membroso' ou 'bem carnudo'. "26 "Será preciso talvez relacionar a insistência crescente no que diz respeito à pureza do sangue nobre, com a mutação progressiva da imagem do fidalgo que sobrevém durante o século XVI sob o efeito da sofisticação dos costumes na Corte. Prova disso é a influência d'O Livro do Cortesão, de Baldassare Castiglione, ou então a elegância exigida por Henrique III dos seus delicados favoritos." ${ }^{27}$ Essa mudança, é bem verdade, não ocorreu sem resistências, como mostra essa pitoresca interpelação de Noël du Fail a um desses cortesãos que ele considerava afeminados:

tua força e tua virtude na verdade não são mais vigorosas do que as de um melro emplumado, tua impotência faz com que não geres mais do que ostras com casca, ou bexigas de porco, que comas pouco e apenas carnes espirituais e delicadas, em oposição à ordem e ao clima deste belo país que olha e muito se aproveita do frio e do Setentrião. Concluo dizendo que se tivesses espermatizado na minha sopa, jamais a comeria. ${ }^{28}$

Henrique IV encabeçou uma reação contra o refinamento excessivo da Corte de seu predecessor, mas a evolução dos costumes curiais em direção a uma maior delicadeza e distinção fez triunfar um modelo de comportamento nobiliárquico mais concordante com as teorias médicas sobre a compleição e sobre a influência da alimentação. O desenvolvimento da esgrima e da dança, que favorecia a leveza e a graça dos gestos, acompanhou e acentuou, sem qualquer dúvida, essa transformação.

\section{Pureza do sangue e hereditariedade}

O sangue não constituía apenas a sutileza do corpo do nobre, mas desempenhava um papel essencial na transmissão hereditária dessa qualidade. No fim da Idade Média e no Renascimento prevalecia a teoria inspirada em Aristóteles e difundida pela medicina galênica, segundo a qual o esperma constituía a quintessência do sangue - e aí encontramos novamente a noção de pureza - a emanação mais sutil, mais purificada, vaporizada sob a forma de uma espécie de espuma. ${ }^{29}$ Ora o sangue, já o vimos, expressava o melhor das substâncias corporais e fazia a

\footnotetext{
${ }^{26}$ Alain Corbin, Jean-Jacques Courtine, Georges Vigarello (dir.), Histoire du corps, Paris, Le Seuil, 2005, t. I, p. 236 (ed. brasileira: Vozes, 2008).

${ }^{27}$ Arlette Jouanna, Faveur et favoris: l'exemple des mignons de Henri III, In: Robert Sauzet (ed.), Henri III et son temps, Paris, Vrin, 1992, pp. 155-65.

${ }^{28}$ Noël du Fail, Contes et Discours d'Eutrapel, 1585, ed. A. Lemerre, 1894, t. II, pp. 29-30.

${ }^{29}$ M. Carnel, Le Sang embaumé des roses, op. cit., pp. 52-3, 90.
} 
junção dessas substâncias com a alma: assim pode-se entender perfeitamente que a ele tenha sido atribuída a tarefa de transmitir, sob a forma de sêmen, a própria essência do ser. Atribuía-se a ele uma forma organizadora. A escolástica medieval identificava o poder ativo do esperma evocado por Aristóteles à virtua formativa de que falavam as fontes médicas. Ele não era, portanto, uma simples matéria. Montaigne maravilhava-se diante do poder de uma gota de semente, que, como ele observava, "traz em si as impressões, não apenas da forma corporal, mas dos pensamentos e das inclinações de nossos pais". Mas ele constatava também, que a ciência médica não tinha outra coisa a propor, à guisa de explicação, senão uma "doutrina muito mais difícil e fantástica do que a própria coisa é" ${ }^{30}$ Os médicos debatiam, com efeito, o problema de saber se a mulher também produzia esperma no momento da geração, um esperma que seria sangue menstrual mal elaborado; Aristóteles considerava que se tratava de uma matéria que recebia a forma do esperma masculino enquanto que Galeno lhe atribuía uma espécie de faculdade formadora. ${ }^{31}$

A crença de que as qualidades paternas se transmitiam pelo sangue não exigia imperativamente explicações científicas precisas, pois repousava na maioria das vezes em uma certeza íntima mais do que em uma reflexão racional. Ela se afirmava como uma evidência sem contestação. "Os reis, príncipes e grandes senhores", escrevia Louis Le Caron, "sobrepujam em excelência os homens mais excelentes a seu serviço, possuem um sêmen natural que os torna dignos de governar, o qual, por sucessão, passa às crianças, e as torna herdeiras dessa mesma excelência, que é chamada de nobreza." ${ }^{32}$ Guillaume du Vair afirmava no seu tratado sobre a eloquência: "Eles transmitem aos filhos, sem qualquer dúvida, as sementes de generosidade ou de coragem de seus pais." ${ }^{33}$ Segundo o já citado Pierre de Saint-Julien de Balleure, "como o sangue é o veículo e o portador dos 'espíritos de vida', nos quais está encerrada a substância da alma, ele age como se fosse um carro que sustenta e carrega essa substância que provém dos pais e dos ancestrais, na longa ordem das gerações, e chega aos filhos que, nascidos de um bom e gentil sêmen, são (conforme a opinião do divino Filósofo Platão) assemelhados aos seus progenitores pela virtude dos espíritos encerrados nessa

\footnotetext{
${ }^{30}$ Montaigne, Les Essais, ed. Pierre Villey, Paris, Alcan, 1930-1941, t. II, chap. 37 (De la ressemblance des enfans aux peres), pp. 859-60.

${ }^{31}$ M. Carnel, Le Sang embaumé des roses, op. cit., pp. 52-3.

${ }^{32}$ Louis Le Caron, Questions Diverses et Discours, Paris, V. Norment, 1579, fol. 83 vº.

${ }^{33}$ Guillaume du Vair, De l'Eloquence françoise (1594), ed. par René Radouant, Paris, 1908, p. 151.
} 
semente". ${ }^{34}$ Pierre de Saint-Julien de Balleure fazia parte do grupo daqueles que acreditavam no determinismo da natureza. Para ele, o sangue nos nobres "maturado por uma longa sucessão de generosas sementes, só pode fazer com que ele ame, honre e siga a virtude, abominando os vícios". ${ }^{35}$ Por esse motivo, ele considerava que "nas monarquias, a nobreza dos fidalgos é substancial, principalmente porque ela é uma nobreza de sangue aportada aos filhos pela substância de seus progenitores e antepassados". ${ }^{36}$

Saint-Julien ressalvava, entretanto: “desde que não haja alianças espúrias”. A fusão de um sangue nobre com um sangue plebeu só iria, segundo ele, abastardar a nobreza. Essa opinião era compartilhada até mesmo por aqueles para quem o nascimento em linhagem inferior não acarretava necessariamente uma propensão ao vício; admitiam, no máximo, a união entre um nobre e uma plebeia, pois a qualidade era transmitida pelos homens, a não ser nos costumes de províncias antigamente imperiais. ${ }^{37} \mathrm{O}$ jurista Guy Coquille, na sua obra Histoire du pays et duché de Nivernois, chegava a usar essa comparação: "A bondade da raça é enfraquecida pela mistura de uma outra raça, mais fraca, da mesma forma como a excelência do vinho é enfraquecida pela água." ${ }^{38}$ Alguns autores chegavam a empregar um epíteto revelador para qualificar as crianças nascidas de uniões desiguais: eram mestiços. Pierre de Saint-Julien de Balleure utiliza também esse termo, como aliás Noël du Fail, François de L'Alouëte, presidente do Conselho Soberano de Sedan, ou ainda Sully, para os quais a multiplicação das alianças entre nobres de espada e de toga teria como consequência "a inexistência de fidalgos que não fossem mestiços" ${ }^{39}$

\footnotetext{
${ }^{34}$ Pierre de Saint-Julien de Balleure, Meslanges Historiques, Lyon, B. Rigaud, 1588, p. 623.

${ }^{35}$ Ibid., p. 602.

${ }^{36}$ Ibid., p. 586 (capítulo: "De Noblesse: et quelle Vertu en est mere"). Ver também o título do capítulo seguinte: "Que la vraye Noblesse a sa source du sang, est substancielle: et pour ce ne souffre ne lus, ny moins".

${ }^{37}$ Étienne Pasquier citava assim os costumes de Chalons na L'Interprétation des Institutes de Justinian (por volta de 1609), p. 53, na edição do Duque Pasquier, Paris, Videcoq aîné, 1847.

${ }^{38}$ Guy Coquille, "Histoire du pays et duché de Nivernois", In: Les Euvres de Maistre Guy Coquille. Paris, J. Guignard, 1665, t. I, p. 463.

${ }^{39}$ P. de Saint-Julien de Balleure, Meslanges Historiques, op. cit., p. 597; N. du Fail, Contes et discours d'Eutrapel, ed. citada, t. I, p. 86; François de L'Alouëte, Traité des Nobles et des vertus dont ils sont formés. Paris: R. Le Manier, 1577, folha. $31 \mathrm{r}^{\circ}-\mathrm{v}^{\circ}$; Maximilien de Béthume, Duque de Sully, Mémoires des sages et royalles aconomies d'Estat, Ed. des trois V verts, s. d., $2^{\mathrm{a}}$ parte, p. 20 (ano de 1601).
} 
Como a nobreza constituía a segunda ordem do Reino, cuja função teórica era de defender esse Reino pelas armas, alguns consideravam que a preservação da pureza de seu sangue era, para os reis, uma tarefa de interesse público. Chegou mesmo a germinar a ideia de um eugenismo que poderia beneficiar toda a coletividade. O humanista Jacques Sadolet, bispo de Carpentras, atribuía essa iniciativa ao rei Francisco I: "Devemos sobretudo louvar", escrevia ele no seu livro sobre a educação das crianças, "a sabedoria de nosso rei Francisco I e seu espírito previdente, digno de um grande príncipe, que se empenhou em fazer com os seres humanos o que outros fazem com seus cavalos ou com seus cães, ou seja, fazer com que, tanto de um lado como de outro, aqueles que se escolhem mutuamente para unir-se pelos laços sagrados do matrimônio, levem em consideração a raça de que provieram, para que, de bons pais, nasçam bons filhos, posteriormente úteis ao rei e à pátria." ${ }^{40} \mathrm{~A}$ comparação sugerida por Sadolet das raças humanas com as espécies animais não era rara. Pode-se encontrar um bom texto condensado sobre essa forma de ver as coisas na obra Ample discours du Roy sur le faict des quatres Estats du royaume de France de Joachim Du Bellay, poema redigido por volta de 1559 ou 1560, segundo um original em latim de Michel de L'Hospital:

E [o Rei] não deixará que um sangue menos corajoso

Venha a abastardar o sangue mais generoso.

Porque se cuidamos tanto de manter a raça

Dos nossos bons cavalos e dos bons cães de caça

Com bem mais razão não deveria um Rei prover

A pureza da raça, seu principal poder? ${ }^{41}$

Alguns autores chegaram até a afirmar que a prática da virtude aprimorava a compleição natural, isto é, como esse aprimoramento se transmitia pela hereditariedade, as raças, ao envelhecer, não podiam senão se aperfeiçoar. Segundo o escritor David Rivault de Fleurance (1571-1616), por exemplo, "o peso e a sujeira corporal embotam a virtude. Por isso, a virtude retira desse corpo esse fardo material e o torna mais leve". ${ }^{42}$ François de L’Alouëte, teórico da nobreza, defendia a mesma ideia ao falar de um "hábito" da raça: "A eficácia dessa virtude

${ }^{40}$ Jacques Sadolet, De Liberis recte instituendis, 1533, ed. e trad. por P. Charpenne. Paris, Plon, 1855 , p. 69.

${ }^{41}$ Joachim Du Bellay, "Ample Discours au Roy sur le faict des quatre Estats du royaume de France", In: CEuvres poétiques, ed. H. Chamard, Paris, Hachette/Droz, 1908-1931, t. VI-1, p. 205, vol. 219-224.

${ }^{42}$ D. Rivault de Fleurance, Les Estats, op. cit., p. 272-3. 
é tal, que pelo fato de passar do pai para o filho, e através do costume de viver de boa maneira, ela se transforma em um hábito da raça que faz aparecer e brilhar aos olhos dos outros, aqueles que dela descendem." ${ }^{43} \mathrm{O}$ hábito da virtude se transforma assim em compleição natural, como defendia um membro do Senado da Sabóia, Guillaume d'Oncieu. ${ }^{44}$ Chegava-se assim a uma verdadeira teoria da hereditariedade dos traços adquiridos. O humanista Pierre de Dampmartin, um íntimo de François d'Alençon, Duque de Anjou, estimava que as crianças cujos "pais e antepassados sempre praticaram o ofício da guerra [...] recebiam, pela virtude do sêmen, esse temperamento de autoconfiança e de coragem adquirido por seus pais pelo hábito e pela amor às armas, e assim, subitamente, ao deixar a infância se encontravam prontos a desprezar os ferimentos e a própria morte". 45

A hereditariedade das qualidades supostamente assegurava a perenidade da ordem social. Em um ambiente mental onde a estabilidade era valorizada e onde as "novidades" apareciam como algo perigoso, todo nascimento comportava um risco: o de uma ruptura, do surgimento de um ser diferente de seu pai. Ao repetir o antigo aforismo inspirado de Horácio: "o semelhante nasce do semelhante", os partidários da continuidade das raças utilizavam a categoria da semelhança como uma grade de leitura do universo, categoria essa cuja onipresença foi mostrada por Michel Foucault, na decodificação do mundo durante o Renascimento. ${ }^{46} \mathrm{Se}$ o filho herdava a natureza de seu pai, ele também refletia a personalidade desse pai; as gerações sucessivas eram como espelhos que refletiam a imagem do antepassado. Cada nascimento era, na verdade, um renascimento. Uma frase de Brantôme (1535-1614) ilustra perfeitamente essa ideologia da repetição: ao pronunciar a oração fúnebre de sua cunhada, ele afirmava, acerca dos filhos da defunta, que eles "eram a verdadeira semelhança e imitação de seus pais, avós, bisavós, ancestrais e seus antigos predecessores, tanto do lado do pai quanto do lado da mãe". ${ }^{77}$ Isto, paradoxalmente, não impedia a iniciativa pessoal do filho de uma

\footnotetext{
${ }^{43}$ Fr. de L’Alouëte, Traité des Nobles, op. cit., fol. $22 \mathrm{r}^{\circ}$.

${ }^{44}$ Guillaume d’Oncieu, La Précédence de la Noblesse, Lyon, J. B. Buisson, 1593, p. 12.

${ }^{45}$ Pierre de Dampmartin, De la Connoissance et Merveilles du Monde et de l'Homme, 1585, fol. $110 \mathrm{v}^{\circ}$.

${ }^{46}$ Michel Foucault, Les Mots et les choses, Paris, Gallimard, 1966, p. 32: "A semelhança desempenhou o papel de construtora no saber do século XVI. [...] o mundo se enrolava sobre si mesmo, a terra repetindo o céu, os semblantes mirando-se nas estrelas, e a erva envolvendo nos seus caules os segredos que serviam ao homem”. (ed. brasileira: Martins Editora, 2007 [10a ed.]).

${ }^{47}$ Pierre de Bourdeille, Senhor de Brantôme, "Oraison funèbre de Madame de Bourdeille", In: CEuvres complètes, ed. por L. Lalanne, Paris, Renouard, 1864-1882, t. X, p. 69.
} 
família ilustre, mas essa parcela de liberdade individual consistia essencialmente em variações sobre um único tema. A hereditariedade das qualidades contribuía assim à legibilidade do sistema de sinais que constituía o universo.

\section{O sangue, fonte de legitimação política}

A superioridade do sangue não fundava apenas a superioridade social, ela legitimava também o exercício do poder. Essa fonte de legitimação foi desde logo invocada para exaltar a dinastia real. Desde o fim da Idade Média, dizia-se que o sangue que corria nas veias de seus membros era clarissimus, claro, transparente, luminoso em comparação com o sangue comum de uma escura cor vermelha. ${ }^{48}$ A ideia de sangue "azul" só surgiu bem mais tarde na França - provavelmente no século XIX - oriunda talvez da Espanha, evocando a brancura da pele que deixava transparecer as veias.

A expressão "Sangue de França” para qualificar o sangue real já era usada no início do XV, ligada à afirmação de que nunca tinha havido um bastardo na linhagem dos soberanos do Reino. ${ }^{49}$ A historiadora medievalista Colette Beaune comparou, sob esse aspecto, a situação francesa àquela que prevalecia na Inglaterra: "Na Inglaterra", observa ela, "o sangue é apenas um dos fatores que conforma o Rei. [...] A França acabava de inventar a noção de direito do sangue, uma força assustadora considerando-se o futuro, e isso a despeito de algumas dificuldades de aplicação imediata. Na França, um louco ou um bebê podem reinar por força de seu sangue. ${ }^{50} \mathrm{E}$ mais ainda, no momento em que se desenvolvia na cristandade latina o culto do sangue do Cristo, o sangue dos reis franceses começou a ser qualificado de santo, sagrado ou milagroso. ${ }^{51}$ Já não era mais a sagração que fazia o Rei, mas sim o sangue. Elaborou-se assim, uma "teologia do sangue da França". Essa teologia acabou sendo desacreditada durante as guerras de religião, principalmente após o massacre de São Bartolomeu. O horror suscitado por essa matança levou, por exemplo, Agrippa d'Aubigné a qualificar o suor de sangue que brotara, segundo se dizia, do corpo de Carlos IX por ocasião da sua morte, "uma amos-

${ }^{48}$ Colette Beaune, Naissance de la Nation France, Paris, Gallimard, 1991, p. 297 da edição de 1985 (Folio-Histoire).

${ }^{49}$ Ibid., p. 300.

${ }^{50}$ Ibid., p. 301.

${ }^{51}$ Ibid., p. 305-6. 
tra apodrecida do sangue grosseiro da dinastia dos Valois". ${ }^{52}$ Contudo, a teoria da sacralidade do sangue real iria mais tarde reencontrar toda sua pujança após o advento de Henrique IV, a despeito de seu parentesco afastado com Henrique III.

A valorização do sangue do rei, entretanto, não era isenta de risco, pois poderia açodar as ambições de seus parentes. A expressão "príncipe de sangue" apareceu, durante o reino de Carlos V, destacando-se pouco a pouco de outras formas concorrentes, tais como "Príncipes de França", "Príncipes da casa real", "Príncipes das flores de liz", "Príncipes reais", ou ainda "Nossos Senhores". ${ }^{3}$ A preposição "de" colocada antes da palavra sangue evidenciava que não é necessário qualificar "aquele" sangue por excelência, o sangue do Rei. Todos aqueles em cujas veias fluía o precioso líquido estimavam-se aptos a participar do governo, isto é, fazer parte do Conselho como "conselheiros natos". Um sermão proferido em 1413, diante de Carlos VI, exprimia bem esta reivindicação: "Os senhores do sangue são membros e parte de seu corpo. Eles são os olhos do corpo do Estado, velando continuamente sobre ele e dedicando-lhe singular afeição, nobreza e especial esmero." ${ }^{54}$

Essas pretensões dos príncipes de sangue serviram de escudo ideológico, no final da Idade Média, para a Guerra do Bem Público e para a Guerra Louca. Elas tiveram também vigorosa expressão nos períodos de minoridade real, circunstâncias essas que deram uma importância ainda maior ao Conselho. Por exemplo, quando Luís XI, faleceu, Carlos VIII foi considerado menor de idade, e os príncipes, encabeçados por Luís de Orléans, futuro Luís XII, tentaram - sem sucesso - impor sua própria influência sobre o Conselho, contra o poder da irmã do novo rei e de seu marido, Anne e Pierre de Beaujeu. No século que se seguiu à morte acidental de Henrique II, em 1559, os oponentes da toda-poderosa família dos Guises, entre os quais havia vários protestantes, tentaram persuadir a opinião pública de que o novo rei Francisco II era ainda menor de idade apesar da existência da ordenança de 1374. Eles queriam fazer valer os direitos do "Sangue de França”, no caso, aquele sangue que fluía nas veias do Duque Antoine de Bourbon e de seu irmão Louis de Condé, aparentemente partidários da Reforma. ${ }^{55}$

\footnotetext{
${ }^{52}$ Agrippa d'Aubigné, “Sonnets épigrammatiques”, $\mathrm{n}^{\circ}$ XVI, In: Euvres complètes pub. por Eugène Réaume e de Caussade, Paris, 1873-1892, Genebra, Slatkine Reprints, 1967, t. IV, p. 337.

${ }^{53}$ Colette Beaune, Naissance de la Nation France, op. cit., pp. 301-2.

${ }^{54}$ Sermão citado ibid., p. 302.

${ }^{55}$ Légitime conseil des Roys de France pendant leur jeune aage, 1560, reimpresso com outros opúsculos expressando as ideias dos conjurados na coletânea intitulada Mémoires de Condé, ed. de 1740, Londres, Cl. Bosse et J. Nillor, vol. 1, p. 225-256.
} 
O fracasso do golpe de estado que eles tentaram - a conjuração de Amboise, em março de 1560 - desacreditou seus esforços, mas suas pretensões tiveram repercussão nos Estados Gerais de Orléans (dezembro de 1560 - janeiro 1561) e nos de Pontoise (agosto de 1561). ${ }^{56}$ A invocação do direito dos príncipes de sangue foi também percebida durante as guerras de religião, através de textos que legitimavam os atos dos dois príncipes, Louis e Henri de Condé. ${ }^{57}$ Os irmãos dos reis, muito especialmente, representavam sério perigo quando os soberanos não tinham filhos: todos os descontentes se agrupavam em torno deles, como foi o caso de François d'Alençon e depois de Gaston D’Orléans. Os esforços dos reis para se prevenir contra este risco consistiam em dar aos seus irmãos um papel ao mesmo tempo honorífico e biológico: honras sem poderes reais. Eles tinham de se contentar com o papel de simples reservatórios do precioso sangue no caso em que o detentor principal viesse a morrer. Uma arenga de Richelieu no Parlamento de Paris em 1634, resume bem esse objetivo:

Existem alguns que têm a honra de ser de sangue real. Mas da mesma forma como o sangue tem seu lugar certo no corpo do homem, nem o sangue nem os príncipes da casa real podem ficar fora de seus lugares naturais sem alterar imediatamente a economia e a saúde do corpo, cujo vigor e vida eles sustentam quando estão no lugar e na compleição que devem ocupar. ${ }^{58}$

Os príncipes de sangue não eram os únicos a reivindicar a participação no Conselho por obra de seu nascimento. $\mathrm{O}$ argumento servia também de pretexto às maiores famílias nobres, algumas das quais, como a família Montmorency, que se proclamavam tão antigos quanto a dinastia real. ${ }^{59}$ Durante as guerras de religião, grandes senhores se ampararam na natureza ilustre de seu sangue para se apresentar como defensores das leis antigas do país, que eles consideravam ter sido desnaturadas pelos conselheiros italianos dos reis. O "protesto", difundido

\footnotetext{
${ }^{56}$ Georges Picot, Histoire des États généraux, Paris, Hachette, 2a ed., 1888,vol. II, pp. 217-20.

${ }^{57}$ Arlette Jouanna, Le devoir de révolte. La noblesse française et la gestation de l'État moderne, 15591661, Paris, Fayard, 1989, pp. 119-79.

${ }^{58}$ BnF, Ms. Fr. 16517, fol. 245 v $^{\circ}$, Arenga do cardeal de Richelieu em presença do Rei Luis XIII no Parlamento (1634).

${ }^{59}$ Ver por exemplo a afirmação feita na Brieve Remonstrance à la Noblesse de France sur le faict de la Declaration de Monseigneur le duc d’Alençon (1576), obra atribuída a Innocent Gentillet: Mérovée "outorgou a um dos seus principais capitães a terra de Montmorency, situada na mencionada Isle de France. De tal forma que os seus descendentes que desde então foram senhores de Montmorency por sucessão de grau em grau sempre ostentaram o título de Primeiro Barão da França”. (p. 58).
} 
por Louis de Condé, em 1567, trouxe à tona esse aspecto com toda a clareza; um comentário junto a esse protesto endereçava-se ao leitor: "A nobreza não jurou [.... e se obrigou de modo especial e solene a conservar o bem público, o estado do Reino, e a Coroa, salvaguardando-a de tudo que lhe pode ser nocivo, e buscando tudo aquilo que pode erguê-la e fazê-la progredir?" ${ }^{60}$ A história das maiores casas nobiliárquicas sempre foi particularmente unida às origens da monarquia e elas consideravam que era de seu dever velar conjuntamente com o rei à preservação da saúde do reino. Essas ideias animaram, de 1574 a 1576, o movimento dos descontentes, nutridos de um imaginário político que buscava seus argumentos nas reconstruções históricas propostas por autores monarcômacos, como François Hotman, Théodore de Bèze ou Philippe Duplessis-Mornay ${ }^{61}$

A valorização do sangue nobre incitou também os fidalgos a considerar que sua efusão nos campos de batalha ou em duelos era uma manifestação da sua superioridade humana. O sangue derramado era para eles uma prova de bravura. A busca de seu derramamento representava para eles uma forma de afirmar ao mesmo tempo a fidelidade à sua raça e a maneira pessoal com a qual eles sabiam encarnar a excelência. Essa tresloucada busca os levava, por vezes, no século XVI, a desconsiderar as regras militares, como demonstram os relatos dos memorialistas que evocaram as guerras da Itália, tais como Fleuranges, Guillaume e Martin du Bellay, Monluc, Boyvin du Villars, Rabutin: os jovens fidalgos se precipitavam sobre "as belas ocasiões para provar suas virtudes e valor", com uma temeridade que beirava a inconsciência. ${ }^{62}$

O esforço dos reis para canalizar a bravura nobiliárquica, tais como a evolução das técnicas e das armas de guerra, desviou para os duelos a necessidade do fidalgo de provar seu valor através de feitos individuais. François Billacois analisou de forma primorosa a idealização do sangue que levou à multiplicação dos duelos na segunda metade do século XVI e no século XVII. O sangue derramado em arena fechada era um "sangue sacrificial" ofertado ao deus da honra, "em uma espécie de potlach destrutivo onde a aristocracia guerreira levava à generosidade

\footnotetext{
60 "Protestation", Les Requestes, protestations, remonstrances et advertissemens faits par Monseigneur le prince de Condé et autres de sa suite, où l’on peut aisément cognoistre les causes et moyens des troubles et guerres presentes, Orléans, Éloi Gibier, 1567.

${ }^{61}$ A. Jouanna, Le Devoir de révolte, op. cit., p. 313-340.

${ }^{62}$ Ver por exemplo o episódio do cerco de "Saint-Damian" relatado por François de Boyvin, Barão de Villars, Mémoires, ed. Michaud et Poujoulat, Paris, 1860, p. 51, col. 1.
} 
ao cúmulo do sacrifício de sua juventude e de seu futuro, para melhor afirmar seu ser". ${ }^{63}$ Era também um "sangue lustral, purificador" que lavava a mácula do insulto: "É somente com sangue que se lava um tal ultraje" diz Corneille através de seu personagem Don Diègue em Le Cid (I, 5). Era finalmente um sangue mesclado em uma espécie de rito de aliança que instituía uma fraternidade entre os vassalos, selada com as feridas infligidas. Esta fraternidade revestiu-se, após a interdição dos duelos, em 1602, de uma conotação contestatória da autoridade real. A reivindicação nobiliárquica de autonomia se-encontrava mais uma vez vinculada ao sangue, cada vez mais difícil de ser tolerada por uma monarquia preocupada com a ordem e a disciplina; reivindicação afirmada agora de forma indireta e eivada de desencantamento, e até mesmo de desespero.

Os oponentes do duelo convidaram os nobres a se converter à economia de seu sangue. Encontra-se uma forma notável desta exigência na obra de Francis Bacon, Charge touching duells (1614): "O dispêndio de sangue é como um dispêndio em dinheiro. Gastar dinheiro por qualquer motivo, por mais fútil que seja, não constitui uma marca de liberalidade, da mesma forma como derramar sangue não é prova de coragem, a menos que a finalidade valha a pena." ${ }^{44}$ Essa cultura da economia era bastante estranha ao ideal nobiliárquico francês. Entretanto, a afirmação progressiva do Estado acabou pouco a pouco obrigando os nobres a se conformar com ela, mesmo ao custo de uma profunda modificação de seus valores. André Corvisier pôde, assim, colocar em oposição a "morte guerreira" de Bayard, à "morte militar" do Cavaleiro de Assas e expor a generalização da ética do sacrifício no seio da nobreza. Essa nova ética representava a adaptação a uma cultura do serviço. Ela era, como o demonstra a análise feita por Hervé Drévillon em seu belo livro L'Impôt du sang. Le métier des armes sous Louis XI, uma maneira de associar a dádiva de si, herdado da prodigalidade aristocrática, ao ideal estatal de um controle global do dispêndio. ${ }^{65}$

\footnotetext{
${ }^{63}$ François Billacois, Le Duel dans la société française des XVI'-XVII e siècles. Essai de psychosociologie historique, Paris, EHESS, 1986, p. 334.

${ }^{64}$ Francis Bacon, Charge touching duells, 1614, p. 13, citado por F. Billacois, Le Duel, op. cit., p. 58.

${ }^{65}$ André Corvisier, La mort du soldat depuis la fin du Moyen Âge, Revue historique, t. CCLIV, 1, 1975, p. 3-30, republicado em Les Hommes, la guerre et la mort, Paris, Economica, 1985, p. 387; Hervé Drévillon, L'Impôt du sang. Le métier des armes sous Louis XIV, Paris, Tallandier, 2005, p. 338. Ver também Hélène Germa-Romann, Du "bel mourir" au "bien mourir" Le sentiment de la mort chez les gentilshommes français (1515-164), Genève, Droz, 2001.
} 
Essa ideologia do sangue, cujas principais características acabam de ser evocadas, foi posta em questão em diversos momentos no decorrer do século XVI, seja em controvérsias filosóficas ou religiosas sobre a importância da hereditariedade ou em conflitos como aquele que opôs, na província do Dauphiné, a nobreza e os plebeus com relação à réalité $e^{66}$ de la taille. ${ }^{67}$ Ela foi também abalada pelos juristas a serviço do poder absoluto do rei. Para estes, a dignidade da nobreza não provinha da natureza, mas era conferida pelo monarca. Este princípio serviu notadamente de orientação para os comissários reais encarregados por Colbert, à partir dos anos 1666-1668, de desentocar os falsos nobres. Em um tratado sobre a nobreza escrito naquela ocasião, um deles, Alexandre Belleguise, resumia assim seu ponto de vista: "A natureza não faz os nobres nem os plebeus [...]. Se percebemos uma diferença entre eles, ela provém do efeito da autoridade do soberano. É uma recompensa pela virtude." ${ }^{68}$ É por esse motivo que no decurso dessas pesquisas nobiliárquicas os entrevistadores não pediam aos nobres testemunhos orais fornecidos pelo seu séquito e atestando o antigo valor de sua linhagem, como se fazia ainda correntemente no século XVI, mas sim atos notariais provando sua filiação e sua nobreza. De qualidade biológica e moral transmitida pelo sangue, a nobreza tendia a se transformar em particularidade do estado civil, submetida a uma legislação que só o monarca podia editar. ${ }^{69}$ Atacado pelos jurisconsultos do rei, o postulado da superioridade inata dos nobres foi também profundamente enfraquecido pela difusão das teses dos Ilustrados sobre a igualdade natural entre todos os homens.

No entanto, apesar de todos estes ataques, a ideia de poder ligado ao sangue tem desfrutado de uma assombrosa longevidade, em razão, por certo, da imemorial fascinação exercida sobre a imaginação por esse líquido vital que veicula mis-

${ }^{66}$ N.T.: O imposto passava a ser cobrado não mais em razão da qualidade do contribuinte, mas em função da qualidade da terra

${ }^{67}$ Emmanuel Le Roy Ladurie, Le Carnaval de Romans, Paris, Gallimard, 1979 (ed. brasileira: Companhia das Letras, 2002)..

${ }^{68}$ Alexandre Belleguise, Traité de la noblesse: suivant les prejugez rendus par les commissaires deputez pour la verification des titres de noblesse en Provence, Toulouse, J. D. Camusat, 1688, p. 12.

${ }^{69}$ Essa evolução é bem descrita no título de Ellery Schalk, From Valor to Pedigree. Ideas of Nobility in France in the Sixteenth and Seventeenth Centuries, Princeton, Princeton University Press, 1986 (tradução francesa: L'Épée et le sang. Une histoire du concept de noblesse, Seyssel, Champ Vallon, 1996, p. 191). E. Schalk, entretanto, critica o conteúdo "racial" da concepção da virtude no século XV. 
teriosamente as qualidades hereditárias de um ser. ${ }^{70}$ Ela também deve sua longa sobrevida à necessidade, por tanto tempo sentida pelos homens, de acreditar que as desigualdades sociais não resultam de uma relação injusta de dominação, mas que são naturais e refletem uma ordem universal desejada por Deus e, portanto, necessariamente justa. $O$ fato de que tenha sido finalmente a noção de pureza do sangue que cristalizou esta crença, com todos os riscos de superinterpretação religiosa que isso implicava, traz muitas informações sobre o sistema de valores que durante tanto tempo prevaleceu no mundo ocidental e sobre a oposição entre o espírito e a matéria, que tanto e tantas vezes impregnou esse sistema.

${ }^{70}$ Jean-Paul Roux, Le Sang. Mythes, symboles et réalités, Paris, Fayard, 1988. 